\title{
A community of shared values? Dimensions and dynamics of cultural integration in the European Union
}

\section{Plamen Akaliyski, Christian Welzel \& Josef Hien}

To cite this article: Plamen Akaliyski, Christian Welzel \& Josef Hien (2021): A community of shared values? Dimensions and dynamics of cultural integration in the European Union, Journal of European Integration, DOI: 10.1080/07036337.2021.1956915

To link to this article: https://doi.org/10.1080/07036337.2021.1956915

\section{(c) 2021 The Author(s). Published by Informa UK Limited, trading as Taylor \& Francis Group.}

\section{Published online: 09 Aug 2021.}

Submit your article to this journal

\section{山 Article views: 191}

Q View related articles 


\title{
A community of shared values? Dimensions and dynamics of cultural integration in the European Union
}

\author{
Plamen Akaliyski $\mathbb{D}^{\mathrm{a}, \mathrm{b}}$, Christian Welze ${ }^{\mathrm{c}, \mathrm{b}}$ and Josef Hien ${ }^{\mathrm{d}, \mathrm{e}}$ \\ aGraduate School of System Design and Management, Keio University, Yokohama, Japan; baboratory for \\ Comparative Social Research, National Research University - Higher School of Economics, Moscow, Russia; \\ 'Center for the Study of Democracy, Institute of Political Sciences, Leuphana University, Lüneburg, Germany; \\ dDepartment of Humanities and Social Sciences, Mid Sweden University, Sundsvall, Sweden; eInstitute for \\ Future Studies, Stockholm, Sweden
}

\begin{abstract}
The series of recent crises (EURO, refugees, backsliding, Brexit) challenge the self-portrayal of the European Union (EU) as a community of shared values. Against this backdrop, we analyse European Values Study data from 1990 till 2020 to assess the level and change in publics' acceptance of the EU's officially propagated values: personal freedom, individual autonomy, social solidarity, ethnic tolerance, civic honesty, gender equality and liberal democracy. We find that EU publics support these values strongly and increasingly over time. The EU-member publics are also remarkably distinct culturally from Eastern European non-EU-nations, especially concerning individual freedoms and gender equality. Simultaneously, however, member nations internalize EU-values at different speeds - alongside traditional religious fault lines that continue to differentiate Europe - in the following order from fastest to slowest: (1) Protestant, (2) Catholic, (3) Ex-communist and (4) Orthodox countries. In conclusion, the EU writ large evolves into a distinct value-sharing community at different speeds.
\end{abstract}

\section{KEYWORDS}

EU-values; European Union; culture; religious legacies

\section{Introduction}

The European Union's (henceforth: EU) accelerated integration and expansion after the Cold War reinforced the framing of a 'Union of Values' in the Treaty on the European Union (TEU) in 1992, more widely known as the Maastricht Treaty. Due to this accord, 'culture' has become the focus of the 'third wave' of European integration, so as to strengthen European identity and increase the legitimacy of EU institutions by promoting 'shared values' and a common heritage as the Union's foundations (Lahdesmaki 2016). The values on which the EU is founded, according to the Treaty on the European Union (EU 2012 [2007]: 17), include 'respect for human dignity, freedom, democracy, equality, the rule of law and respect for human rights, including the rights of persons belonging to minorities [...,] pluralism, non-discrimination, tolerance, justice, solidarity

CONTACT Josef Hien josefhien@googlemail.com $\Theta$ Department of Humanities and Social Sciences, Mid Sweden University, Sundsvall, Sweden; Institute for Future Studies, Stockholm, Sweden

The authors report no potential conflict of interests.

This article has been corrected with minor changes. These changes do not impact the academic content of the article.

(c) 2021 The Author(s). Published by Informa UK Limited, trading as Taylor \& Francis Group.

This is an Open Access article distributed under the terms of the Creative Commons Attribution-NonCommercial-NoDerivatives License (http://creativecommons.org/licenses/by-nc-nd/4.0/), which permits non-commercial re-use, distribution, and reproduction in any medium, provided the original work is properly cited, and is not altered, transformed, or built upon in any way. 
and equality between women and men.' Promoting these values, referred to throughout this article as 'EU-values,' the EU aims at achieving an 'ever closer union among the peoples of Europe' (Treaty of Lisbon 2007). These documents demonstrate that the EU is in a process of framing its ongoing economic and political integration within an identity-forming cultural narrative that centres on support for shared values (Akaliyski and Welzel 2020).

However, the progression of these ambitions at cultural integration confronted a series of crises that cast doubts on whether the proclaimed Union of Values actually exists or will ever be achieved. The financial crisis in 2008 brought divisions over the interpretation of solidarity between Northern and Southern member states. The refugee crisis gave rise to Eurosceptic populism and unmasked divisions among European elites and populations. The rule of law crisis in Poland and Hungary showcased that the shared value fundament embodied in Article 2 of the TEU is contested by some member state governments (Kelemen 2020; Wolkenstein 2021).

The ability to make collective decisions in response to challenges depends, among other factors, on shared societal values (e.g. Guiso, Herrera, and Morelli 2016; Hien 2019; van Houwelingen, ledema, and Dekker 2019). Although not the only condition, a consensus on a set of fundamental values is vital for the sustainability of the EU as a democratic community (Habermas 2012). Yet, the seeming disunity among EU member states in how to respond to the above challenges questions whether a union of values as proclaimed in the Maastricht Treaty has ever emerged. Therefore, we ask in this study: has the EU-citizenry come closer to a union of shared values or has it moved further away from this ideal during the last three decades of integration?

Previous studies focusing on similar research questions provide contradictory answers (Akaliyski 2019; Oshri, Sheafer, and Shenhav 2016; van Houwelingen, ledema, and Dekker 2019; van Houwelingen et al. 2021). Their limited and not entirely overlapping time span, as well as the differences in the type of values they examine could be the reasons for their disagreement. This inconclusiveness of previous research requires a re-examination of the question of value homogeneity and convergence-vs-divergence among EU-member nations over a long period and with a wider selection of societal values related to those officially propagated by the EU.

We break down our overarching research question whether the EU-nations could be considered a community of shared values into five more specific questions:

(1) Do the EU-member nations endorse the values promoted by the EU?

(2) Are these values changing in the direction desired by the EU?

(3) Are the value distances between the EU-member nations negligibly small?

(4) Are the values of the EU-member nations converging - within the EU and between previously identified culture zones?

(5) Are the values of the EU-member nations distinct from those of other European nations?

To answer these questions, we use data from the second to the fifth (pre-released) European Values Study (EVS 2020), which covers the time span from roughly 1990 till 2020. We operationalize EU-values in seven domains that resemble as close as possible those explicitly advocated in the EU treaties. We analyse these domains separately as well 
as in a combined EU-values index. We calculate average EU-value distances between EUmember nations and examine them cross-sectionally and longitudinally, looking at change in value distances over time.

In the next section, we review the literature on each of the specific research questions and derive five testable hypotheses. Thereafter, we present our data, operationalization of values, and methodology, followed by our findings. To anticipate our main result, we identify an overall strong support and increasing enculturation of EU-values, albeit at different paces depending on the nations' religious heritage. The article closes with conclusions and a discussion of its implications.

\section{State of the art}

\section{Prevalence and change in EU-values among member states}

As a 'value entrepreneur,' the EU provides a cultural narrative for member states to follow (Gerhards 2010; Gerhards et al. 2009). The fundamental values that comprise this narrative are part of EU treaties and legislation, which have priority over national law. Accession candidates also need to implement the entire body of EU legislation ('Acquis Communautaire') before they can join. Even the countries of the European Free Trade Association (henceforth: EFTA) enact a substantial proportion of the EU's legislation. The EU actively promotes its values through various initiatives, recommendations, and impositions on the member states (Toggenburg and Grimheden 2016). Scholars of EU law argue that the values, as stated in Article 2, are not just lofty ideals but have the status of legally binding principles (Kochenov 2017). In the preceding treaties and in the Copenhagen Criteria the wording was still 'principles;' only with the TEU the term 'values' appeared. Regardless of the label, it is consensual that these values can be enforced through the sanction mechanisms in Article 7 of the TEU (Hellquist 2019; Spieker 2019). An Article 7 procedure has, for example, been initiated against Poland for infringement on these values during the rule of law crisis. Moreover, the EU has put the European Union Agency for Fundamental Rights in charge of monitoring the infringements of Article 2 values in member states (Toggenburg and Grimheden 2016: 1093). All this suggests that the Union has certain leverage in promoting and enforcing theses values in its member states. Moreover, these values are the basis of European Common Foreign and Security Policy (CFSP). Pursuing this 'normative power Europe' (Manners 2002), the Union has become the most active executor of foreign policy sanctions world-wide (Hellquist and Palestini 2020).

Accordingly, Oshri, Sheafer, and Shenhav (2016) find that with each year of EUmembership, support for democratic values has grown steadily among EU-nations, concluding that the EU is successful in socializing these values among its citizens. Akaliyski and Welzel (2020) also find that, since the end of the Cold war, EU-nations have increased their emphasis on emancipative values, which overlap largely with some of the key values promoted by the EU, especially those related to individual freedom and gender equality. van Houwelingen et al. (2021) also find increasing support for personal freedom and redistribution, but not cosmopolitanism.

Furthermore, growing existential security and increasingly enabling living conditions in most EU-countries propel an emancipatory value change towards equality, freedom, tolerance and pro-sociality (Welzel 2013), all of which represent EU-values. The EU aims to 
increase existential security and to improve living conditions in member states through the economic regulatory integration and the European structural and cohesion funds targeted at the economically weaker parts of Europe. According to Inglehart's postmaterialism theory and Welzel's human emancipation theory, socioeconomic development, urbanization, mass education, and a rising sense of existential security, agency and a promising life prospects, all foster post-materialist and emancipative values. These values closely resemble several domains of the EU-values (Inglehart 1997; Welzel 2013). Since the EU is one of the most prosperous and peaceful areas of the world, we can expect that the EU-values would find the most hospitable soil among wealthy European countries, and these values might be prevalent even without any EU promotion.

\section{Size of value distances among EU-nations}

Previous research identifies considerable value diversity across Europe as well as inside the EU. Three of the most prominent cultural maps of the world - drawn by Inglehart and Welzel (2005), Schwartz (2006), and Welzel (2013) - depict Europe as culturally more diverse than any other part of the world. These maps exhibit distinct Northern and Southern as well as Eastern and Western cultural clusters in Europe, still reflecting the divisions originating in the Reformation and the imposition of Soviet-type communism. The Western European countries are conventionally grouped into a Protestant, a Catholic, and an English-speaking cluster (Inglehart and Baker 2000) or Reformed West (Protestant) and Old West (Western European Catholic) (Welzel 2013), based on their close cultural proximity and distinction from other culture zones. The former communist countries are further divided into two clusters: the Returned West comprises ex-communist countries with a Catholic or Protestant tradition that joined the EU, while the Orthodox East includes the ex-communist countries with a Christian-Orthodox tradition, most of which remain outside the EU. These studies underline the significance of religious-historical legacies in placing societies on a path-dependent trajectory of cultural development (Inglehart and Baker 2000).

Scholars also find that the further eastward one moves, the larger the value differences to Western Europe grow (Fuchs and Klingemann 2002; Gerhards 2007; Gerhards and Hoelscher 2003). Accordingly, EU-nations are closer to each other when it comes to embracing democratic (Oshri, Sheafer, and Shenhav 2016) and emancipative values (Akaliyski 2019) than to countries outside the EU.

\section{Convergence on EU-values}

Few studies examine temporal change in value distances within the EU. For instance, Akaliyski (2019) and Akaliyski and Welzel (2020) find that, since the end of the Cold War, EU-nations have reduced their distances on emancipative values, although the second study also identifies pronounced differences between countries based on their religious traditions. However, these two studies are limited in their temporal range until around 2008 , for which reason they fail to highlight recent dynamics.

Van Houwelingen, ledema, and Dekker (2019) use data from the European Social Survey covering the period from 2002 till 2016 and arrive at a different conclusion regarding value convergence in the EU. Among the three core political values examined, they find a divergence in LGBT-aversion and immigration acceptance. Convergence is observed only regarding Euroscepticism, which has increased, contrary to the aspirations 
of the EU. A follow-up study examining trends in three core political values with EVS data from 1990 to 2017 also discovers an EU-wide divergence on individual-sexual freedom but a convergence on redistribution and cosmopolitan values (van Houwelingen et al. 2021).

In spite of these differences in the empirical findings, all four studies hypothesize that the initial heterogeneity has decreased gradually over time. The authors suggest that the expected decrease is due to the EU's intentional value promotion. Since all member states are exposed to the EU's value script, deviances in any particular member nations may receive more attention and cause greater pressures to comply to EU standards.

Furthermore, through its four fundamental freedoms, the EU enabled the movement of people, goods, capital, and services, thus allowing a closer exchange between the member nations. According to Bonikowski (2010), cultural convergence could be achieved through closer cross-country interactions. The EU institutions promote such interconnections between EU citizens in all aspects of life, thus supposedly increasing the diffusion of values across the member nations.

Finally, the European integration process has increased the similarities between member states in societal organization, living standards, and existential security, which are important predictors of cultural values (Schwartz and Bardi 1997; Inglehart and Baker 2000). Market economies, democratic institutions and the fulfilment of demanding rule of law standards are required from all accession candidates to achieve full membership. Through the structural and investment funds, the EU redistributes resources to less developed regions, thus narrowing the gap between poor and rich countries. And even though pronounced differences persist alongside East/West and North/South divisions, these differences have decreased significantly since the end of the Cold War. This may be an additional factor contributing to value convergence throughout the EU.

\section{Distances to other nations}

Based on previous research (e.g. Akaliyski 2017, 2019; Akaliyski and Welzel 2020; Oshri, Sheafer, and Shenhav 2016), we expect that the EU-nations have become more culturally distinct from other nations, especially regarding values promoted by the EU. These values were chosen on purpose to appeal to the EU-public. Most of these values are commonly perceived as being rooted in Europe's Occidental civilizational heritage - democracy in ancient Greece, rule of law in the Roman Republic, freedom and equality in the Enlightenment and solidarity in Christianity. Although they have subsequently spread worldwide, especially to countries of European descent and at high levels of socioeconomic development, these values continue to be a source of identity and pride among Western European publics (Akaliyski and Welzel 2020).

Even though values such as democracy and human rights are propagated with the claim of universal validity (United Nations 1948; Sen 1999), these values are abstractions and allow for a variety of specific interpretations, which may differ from the originally intended. A study by Kirsch and Welzel (2019), for example, finds that even though democracy is almost universally accepted as a preferred form of government, people in autocratic states exhibit a so-called 'authoritarian notion of democracy,' which conflicts with the principles of liberal democracy. Therefore, when we examine more specific manifestations of abstract values, we may discover that EU-citizens share these values more widely. Previously, Oshri, Sheafer, and Shenhav (2016) and Akaliyski (2019) confirm 
that EU-nations are distinct from the rest of the world when it comes to democratic and emancipative values, respectively.

Before we enter the next section, which lists our hypotheses, a qualifying remark related to the EFTA-publics is due. All three EFTA-nations (i.e. Iceland, Norway, and Switzerland) are core Western European countries of Protestant origin that are historically closely linked and geo-politically allied with the EU's founding nations and culturally close to them, ever since. For these reasons, we expect the EFTA-publics to be exempted from cultural divisions alongside the member/non-member separation with respect to the EU. Thus, we hypothesize that the member/non-member division is primarily relevant for Eastern Europe and much less so for Western Europe.

\section{Hypotheses}

Our review of the literature informs a set of five hypotheses:

\section{Support hypothesis $(\mathrm{H} 1)$}

On average, the EU-publics support the values propagated by the EU to a considerable degree. Our criterion for confirming this hypothesis is that on our EU-values scale ranging from 0 to 100, the EU-citizenries achieve an average score of 50 points at least.

\section{Increase hypothesis ( $\mathrm{H} 2)$}

The endorsement of the EU-values among EU-nations has increased over time. We assess this hypothesis by testing whether there is a statistically significant increase in support for EUvalues between the first and the last survey covered.

\section{Consensus hypothesis (H3)}

The value distances among EU-member states are negligibly small. As an arguably negligible distance score on our 100-point scale, we consider 10 points or less.

\section{Convergence hypothesis (H4)}

The value distances between the EU-publics have decreased from 1990 to 2017. We test this hypothesis by assessing the statistical significance of the change in value distances across EUpublics.

\section{Distinction hypothesis (H5)}

The values of the EU-nations are distinct from Europe's non-EU nations. We evaluate this proposition by testing the statistical significance of the value distances between the EUnations, on the one hand, and the publics outside the EU (and EFTA), on the other. We distinguish between non-EU-members that are part of EFTA and those that are not as the nature of their relationship to the EU differs substantially, as explained earlier. 


\section{Data and operationalization}

\section{Data and sample}

We use data from the European Values Study (EVS 2020), which consists of nationally representative samples of European residential populations $(N=1,000-3,000)$ surveyed repeatedly in five waves. We analyse the longest period for which data are available. Since the first EVS wave in 1981 included too few countries, we begin our analysis with the second wave, collected mostly in and around 1990. The latest wave of surveys (wave five) was conducted between 2017 and 2020. For convenience, we denote the dates of the earliest and latest survey waves as '1990' and "2017' when most countries were surveyed. We include only countries surveyed both at wave two and five. Our dataset, thus, includes 19 EU-countries, which represent all major enlargements and previously defined culture zones. Great Britain and Northern Ireland were surveyed separately, but data are available only for Great Britain. For comparison with non-EU publics, we use data for seven European publics outside the EU (i.e. Albania, Azerbaijan, Armenia, Belarus, Georgia, Russia, and Serbia) as well as three EFTA-publics (Iceland, Norway, and Switzerland).

\section{Operationalization of values}

To tap EU-values, we examine all EVS items and select those most closely resembling the values listed in Article 2 of the Maastricht Treaty (see introduction). It is impossible to measure each of the 13 values enumerated in Article 2 by a separate value construct because the EVS questionnaire is not designed to match in perfect correspondence the EU-values, as listed in Article 2. Therefore, we select value items that are related to as many of the EU-values as possible and group them based on their conceptual similarity.

Accordingly, we identify seven value domains, each comprising three items, with the exception of gender equality (just one item) and social solidarity (five items). The selection of items is limited to those available in both the second and fifth EVS waves. We make an exception for the values of solidarity and liberal democracy, for which data are collected since wave three in around 1999. Below, we list the seven domains of EU-values - personal freedom, individual autonomy, social solidarity, ethnic tolerance, civic honesty, gender equality, and liberal democracy - with their corresponding items. Each EU-value domain consists of items derived from the same thematic field in the EVS questionnaire, which suggests their conceptual similarity. We report Cronbach's alphas for each value domain and the EU-values index to document their degree of internal coherence. It should be noted, however, that we create these constructs following a formative logic, meaning that our grouping rationale is the items' conceptual proximity in content, rather than their mere statistical correlation (Welzel et al. 2021). Nevertheless, with the exception of individual autonomy, all domains and the overall EU-values index exhibit a high level of internal reliability. Our analytical-term EU-values represents a summary construct of the values deemed foundational for the EU.

(1) Personal freedom (Cronbach's alpha $=.91$ )

- F118 - Justifiable: Homosexuality 
- F120 - Justifiable: Abortion

- F121 - Justifiable: Divorce

(2) Individual autonomy (Cronbach's alpha $=.49$ )

- A029 - Important child qualities: Independence

- A034 - Important child qualities: Imagination

- A042 - Importance child qualities: Obedience (reversed)

(3) Social solidarity (wave 3 onwards) (Cronbach's alpha $=.86$ )

- E157 - Feel concerned about: Europeans

- E159 - Feel concerned about: Elderly people

- E160 - Feel concerned about: Unemployed people

- E161 - Feel concerned about: Immigrants

- E162 - Feel concerned about: Sick and disabled people

(4) Ethnic tolerance (Cronbach's alpha $=.89$ )

- A124_02 - Accepting as neighbours: People of a different race

- A124_05 - Accepting as neighbours: Muslims

- A124_06 - Accepting as neighbours: Immigrants/foreign workers

(5) Civic honesty (Cronbach's alpha =.75)

- F114 - Justifiable: Claiming state benefits which you are not entitled to (reversed)

- F116 - Justifiable: Cheating on taxes (reversed)

- F117 - Justifiable: Someone accepting a bribe (reversed)

(6) Gender equality

- C001 - When jobs are scarce, men should have more rights to a job than women (reversed)

(7) Liberal democracy(wave 3 onwards) (Cronbach's alpha =.76):

- E114 - Political system: Having a strong leader (reversed)

- E116 - Political system: Having the army rule (reversed)

- E117 - Political system: Having a democratic political system

EU-Values Index (Cronbach's alpha $=.78$ )

For ease of numerical interpretation, we rescale each item to vary between a minimum of 0 and maximum of 100 . Then, we compute domain-wide scores as the average across the grouped items. Accordingly, the domain-wide scores also vary between 0 and 100 . We aggregate the data to the national level, thus focusing on population averages in disregard of the variation within national publics. By using the sample means in these values, we capture the central tendencies and, hence, the gravity fields of the different national cultures, which is in line with the very concept of national culture (Akaliyski, Bond, and Welzel 2021). Besides, sample means are close to the median and mode in each national public and the distributions of the individual respondents are typically meancentred and single-peaked, for which reason the sample means provide indeed a valid representation of each national culture's central tendency in values at a given time.

We regard national culture as the prevalent value framework in a society that subjects all individuals within that society to the same normative group pressures (Fischer and Schwartz 2011; Schwartz 2014). This is in line with a popular definition by Fischer and Schwartz (2011: 1140) who describe national culture as the latent normative value system, external to the individual, that underlies the functioning of societal institutions [and] does not require consensus at the individual level.' These authors also argue that 
Table 1. Correlational matrix among value domains and EU-values index $(\mathrm{N}=56)$.

\begin{tabular}{|c|c|c|c|c|c|c|c|c|c|}
\hline & & 1 & 2 & 3 & 4 & 5 & 6 & 7 & 8 \\
\hline 1 & Personal freedom & 1.00 & & & & & & & \\
\hline 2 & Individual autonomy & 0.64 & 1.00 & & & & & & \\
\hline 3 & Social solidarity & 0.12 & 0.06 & 1.00 & & & & & \\
\hline 4 & Ethnic tolerance & 0.35 & 0.06 & 0.17 & 1.00 & & & & \\
\hline 5 & Civic honesty & 0.19 & 0.29 & 0.12 & 0.25 & 1.00 & & & \\
\hline 6 & Gender equality & 0.84 & 0.49 & 0.10 & 0.47 & 0.28 & 1.00 & & \\
\hline 7 & Liberal democracy & 0.57 & 0.32 & 0.09 & 0.58 & 0.33 & 0.57 & 1.00 & \\
\hline 8 & EU-values & 0.90 & 0.64 & 0.26 & 0.61 & 0.41 & 0.90 & 0.74 & 1.00 \\
\hline
\end{tabular}

even small value differences aggregated at the national level indicate significant institutional and policy differences between countries, which in turn 'may generate substantial intergroup and international conflict' (Fischer and Schwartz 2011: 1140). Studies also find that subnational cultural groups based on religion, geography, social class, ethnicity, cohort and gender locate consistently within their respective national cluster (Inglehart and Welzel 2005; Minkov and Hofstede 2012, 2014a, 2014b). For all these reasons, we conclude that nationally aggregated individual-level values are meaningful measures of the countries' cultural gravity centres.

Table 1 displays the intercorrelation between the domains and the overall EU-values index. All items are correlated positively with each other and are correlated with EU-values at an $r$ between .26 and .90 . The values of social solidarity and civic honesty correlate less closely with the other values, yet their inclusion is not based on their statistical correlation but their conceptual status. We do not treat our EU-values as a uniform latent construct but as a summative index of a 'formative' rather than 'reflective' kind. Our overall EUvalues index measures the average public support of the values promoted by the EU. To consider the differences between the domains, we also analyse them separately where parsimony allows.

\section{Culture zones}

We group countries into culture zones following the conventions in previous research, most of which distinguish between religiously defined groups of countries in Europe plus an overriding ex-communist group (Inglehart and Baker 2000; Schwartz 2006; Welzel 2013). These classifications refer to the historically predominant religion in a country, even though at present the composition of denominations may have changed or the majority of the nation consider themselves atheists or agnostic. We create four culture zones in the EU, based on their historical background: (1) Protestant West: all non-former communist European nations with historically predominant Protestant traditions; (2) Catholic West: all historically Catholic non-former communist European nations; (3) Excommunist West: all former communist nations with either Catholic or Protestant religious traditions; and (4) Orthodox East: nations with mostly Eastern-Orthodox traditions (see Appendix for country categorization). We do not distinguish between ex-communist and non-ex-communist Orthodox nations because we have only members of the former in our dataset (Greece and Cypress were not surveyed). We compare these culture zones also with nations outside the EU, both Eastern European and members of EFTA. 


\section{Methods}

To answer our research questions, we first evaluate the level of endorsement of EU-values among EU-nations at the beginning and at the end of the time period. Furthermore, we estimate the rate of change and test for statistical significance using simple linear regression where the only predictor is the wave of the survey. We perform these analyses for all EU-publics together and separately for each culture zone. We focus on the cumulative change from the beginning to the end of the period because values change slowly (Inglehart and Baker 2000) and we want to avoid capturing random measurement error between surveys conducted within a short time period. Since each nation is measured at two time points, we compute cluster robust standard errors.

Furthermore, we examine convergence and divergence - again among all EU-nations and between culture zones - using regressions with undirected dyadic data, analogous to the approach in the analysis of value distances in Akaliyski (2019). We create unique pairs of countries as units of analysis, which allows the computation of total value distance between nations and testing for convergence or divergence by looking at the change in value distances over time. In our dyadic data, nations appear multiple times within pairs of countries (e.g. Austria-Bulgaria, Austria-France, Bulgaria-France), leading to a correlation of error terms (Aronow, Samii, and Assenova 2015). To correct for this, we compute twoway cluster-robust standard errors (Cameron, Gelbach, and Miller 2011). In the results section, we present our findings in figures to ease comprehension. We also present confidence intervals to visualize statistical significance.

Lastly, we use multidimensional scaling (Borg, Groenen, and Mair 2013) to plot all countries in a two-dimensional space using data on all seven value domains - similar to the approach used in Schwartz (2006). In this method, the two dimensions have no inherent meaning. We present a correlation matrix to demonstrate how the dimensions relate to our EU-value domains. The purpose is to gain a more intuitive understanding of the cultural clustering in the EU and to evaluate the relevance of previously defined culture zones. We use Stata, version 16 for all analyses. For creating the graphs, we use the freeware R-4.0.2.

We conduct all our analyses of change within the same groups of countries in order to ensure their comparability. Therefore, we treat EU-membership as a fixed property, using the status of countries as of 2017. This means that in the analyses for 1990, many of the countries treated as EU-members are prospective members as of that point in time, while the UK (Great Britain) was included as a member state because it was still part of the Union within the analysed period.

\section{Results}

To begin with the first two research questions about the degree and change in support for EU-values, Figure 1 presents the level of endorsement for each of the seven EU-value domains as well as the overall EU-values index, in 1990 and 2017. At the end of the Cold War, member nations emphasized EU-values to a significant degree, albeit less so regarding personal freedom and individual autonomy. By 2017, all of the seven value domains pass our threshold of 50 points. This is due to a substantial increase in support for almost all EU-values, especially personal freedom, and gender quality. Ethnic tolerance, civic 


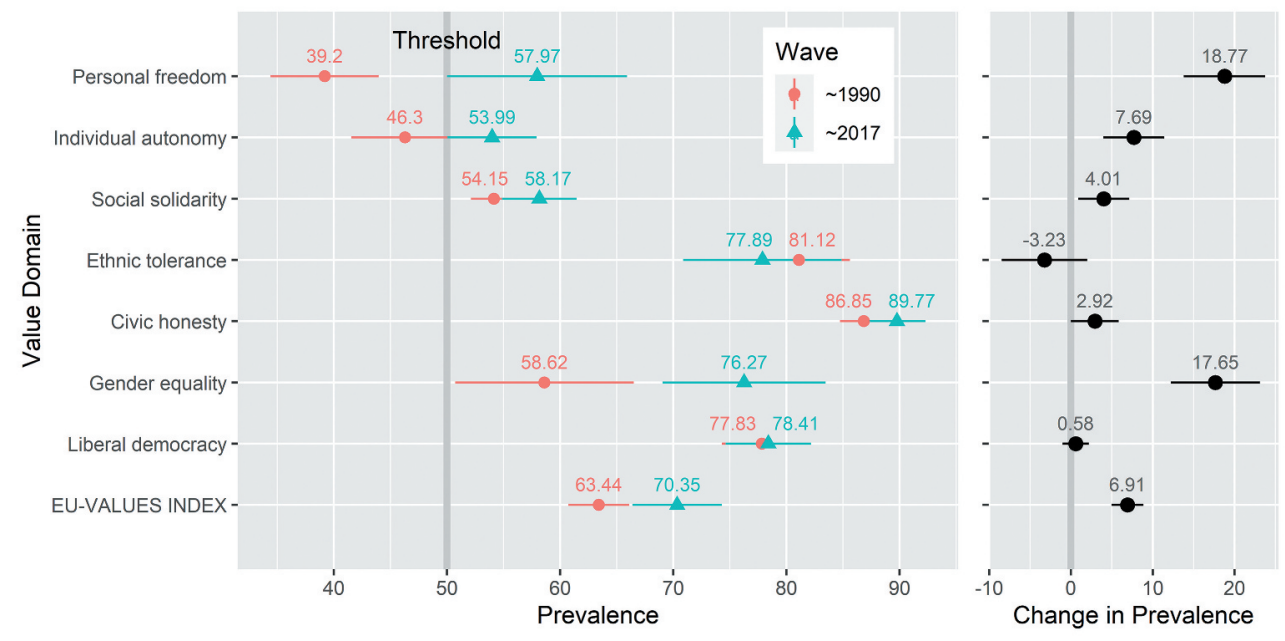

Figure 1. Prevalence and change in EU-values among 19 EU-member states.

honesty and liberal democracy do not change significantly, but member nations endorse them all to a considerable degree. Thus, these observations fully confirm our Support Hypothesis ( $\mathrm{H} 1)$. The EU-values index has also increased significantly by 6.91 points, which confirms $\mathrm{H} 2$ that the support for EU-values has increased over time, even though this is due to the increase in only four of the seven value domains.

Moving forward to the third and fourth research questions about the size of and the change in value distances within the EU, Figure 2 again presents mixed evidence. In 1990, distances on the overall EU-values index and on four of the value domains remain at or below our threshold of 10 points. By 2017, distances on three domains have grown significantly, while only those on individual autonomy have decreased. As a result, EUnations are now significantly divided over personal freedoms, ethnic tolerance, and
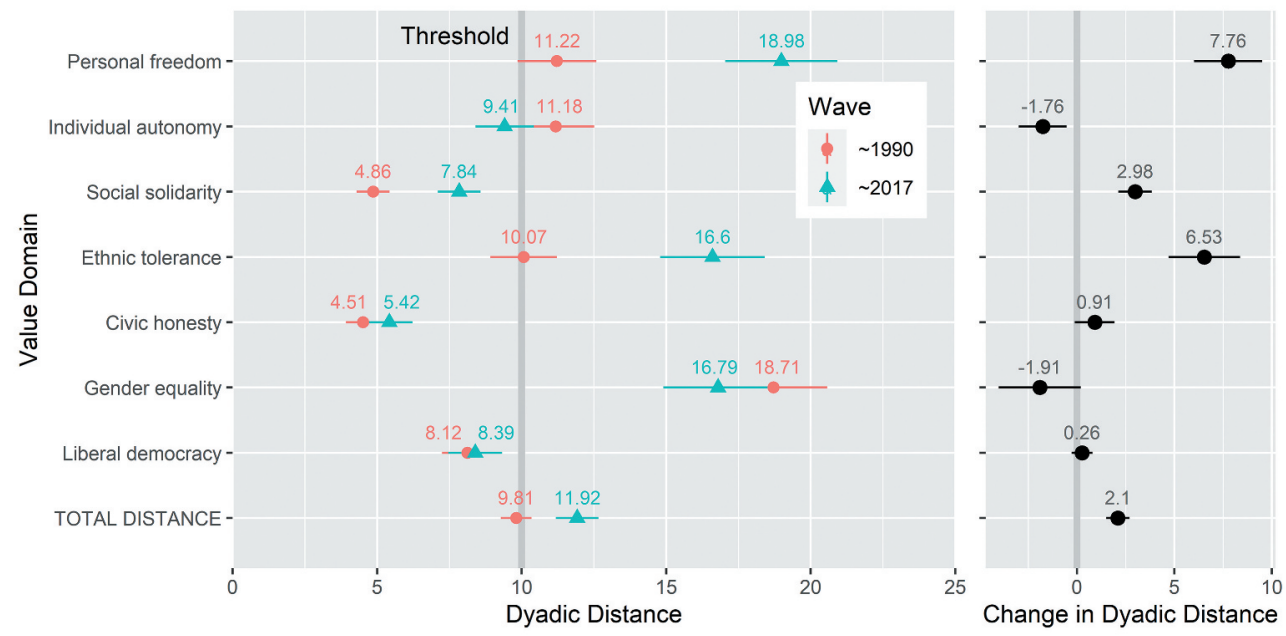

Figure 2. Dyadic distances and change in distances in EU-values among 19 EU-member states. 
gender equality. Interestingly, the most gender-equal Protestant nations almost run out of room for improvement on our scales, which offers other nations an opportunity to catch up. Despite this mixed evidence, the total value distance in 2017 is significantly above the threshold of 10 scale points, thus disconfirming the Consensus Hypothesis $(\mathrm{H} 3)$. Moreover, the total value distance has increased significantly by 2.1 points, thus also disconfirming our Convergence Hypothesis (H4).

Figure 3 shows the level of support for and the change in EU-values within culture zones. Protestant Western nations score the highest, followed by the Catholic West, Excommunist West and lastly by the Orthodox East. The evidence is in line with Inglehart and Baker (2000) observations of the ranking of culture zones, yet not with these authors' observation of an equally paced value change across culture zones. Instead, we see a progression, by which the strongest supporters of EU-values also make the biggest gains, thus further increasing their lead. Catholic Western and Ex-communist Western nations increased their support of EU-values but more slowly than among Protestant publics - by 1.66 and 4.11 scale points, respectively. Orthodox Eastern nations, for their part, have not significantly increased their anyways lower support for EU-values. Hence, over time culture zones have become even more distinct, again disconfirming the Convergence Hypothesis.

Figure 4 presents more details about the prevalence and change in each value domain within the four culture zones. The biggest increases in support for EU-values happened in the domains of personal freedom and gender equality, followed by individual autonomy and social solidarity. Support for EU-values in the remaining domains grew more slowly and is mostly statistically insignificant. Support for EU-values in the Protestant West has almost reached the scale ceiling in three domains - ethnic tolerance, civic honesty, and gender equality. Endorsement of these values is likely growing further in these countries but have in the meanwhile extended to new frontiers that the current items do not capture (such as LGBTQ+ rights, animal wellbeing, veganism, sustainability, etc.). Therefore, our measure possibly even underestimates the size of the real and continuously growing value gap between the Protestant West and the rest of Europe.

Another remarkable observation is the decrease in ethnic tolerance among Excommunist Western nations by a substantial 11.1 scale points. This obvious decline is not statistically significant at the conventional level $(p=.09)$ due to the uneven change

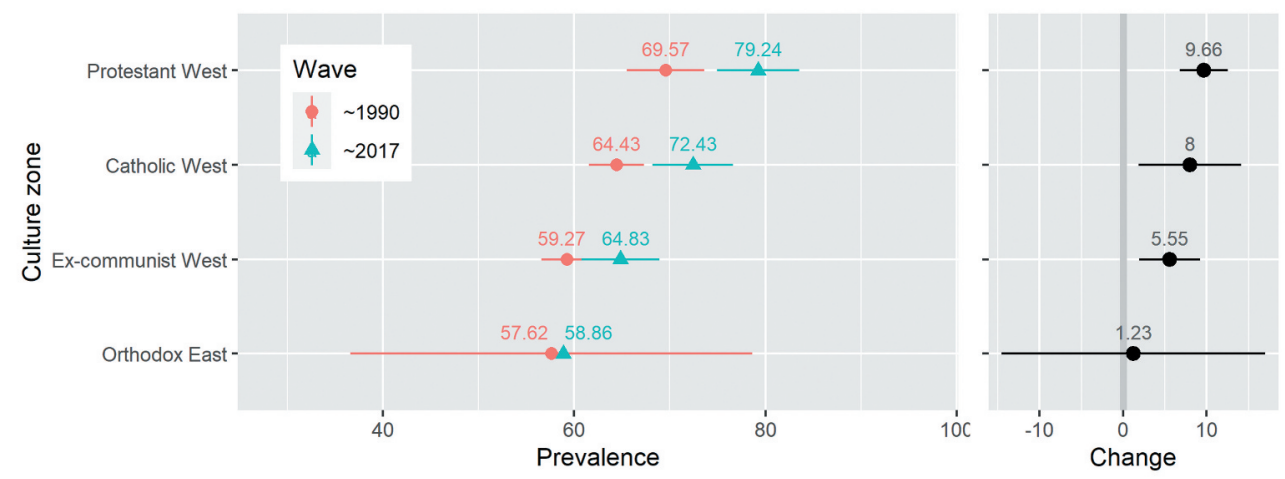

Figure 3. Prevalence and change in EU-values among 19 member states by culture zone. 


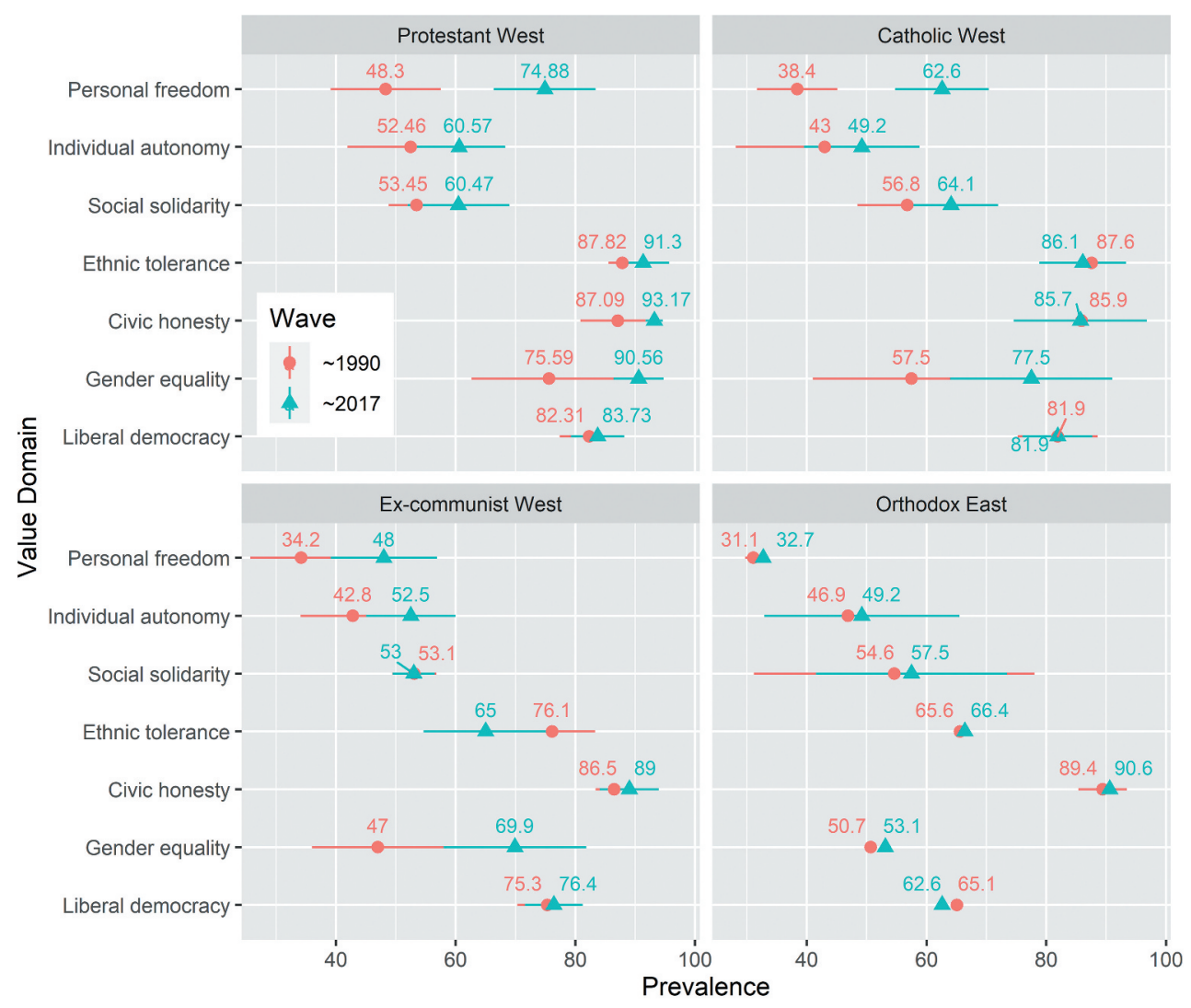

Figure 4. Prevalence of EU-value domains in 19 member states by culture zone. Note: confidence intervals (Cls) for Orthodox countries were excessively large due to the group comprising only two countries. Cls were not presented if they exceeded the limits of the plot.

among this group of countries. Upon further investigation (see Figure A1 in the Appendix), we find that this drop is primarily due to sharply decreasing tolerance in Czechia (27.1 points), Lithuania (18.4), Slovakia (18.3), and Hungary (16.5). Among the other Ex-communist nations, the drop is much smaller, while Slovenians have even increased their ethnic tolerance by 15 points.

Figure 5 sheds more light on the cultural dynamics between culture zones. In 1990, the differences within each of the four culture zones are considerably smaller (between 5.01 and 8.25 points) than the average distance among all member states, which, as reported in Figure 2, is 9.81 points. Protestant Western nations have decreased their average distance to each other by 1.81 points, while nations within the Ex-communist West and the Orthodox East have become culturally more diverse over time by 1.6 and 3 points, respectively. The average distance between EU-nations in the Protestant and Catholic West remains relatively small at 9 points. Yet, the distances between EU-nations in the Protestant West, on the one hand, and the Ex-communist West and East, on the other, have grown by 3.83 and 6.93 and reach 16.4 and 21.01 points, respectively. The biggest gap separates the Protestant West from Eastern European countries outside the EU (23 


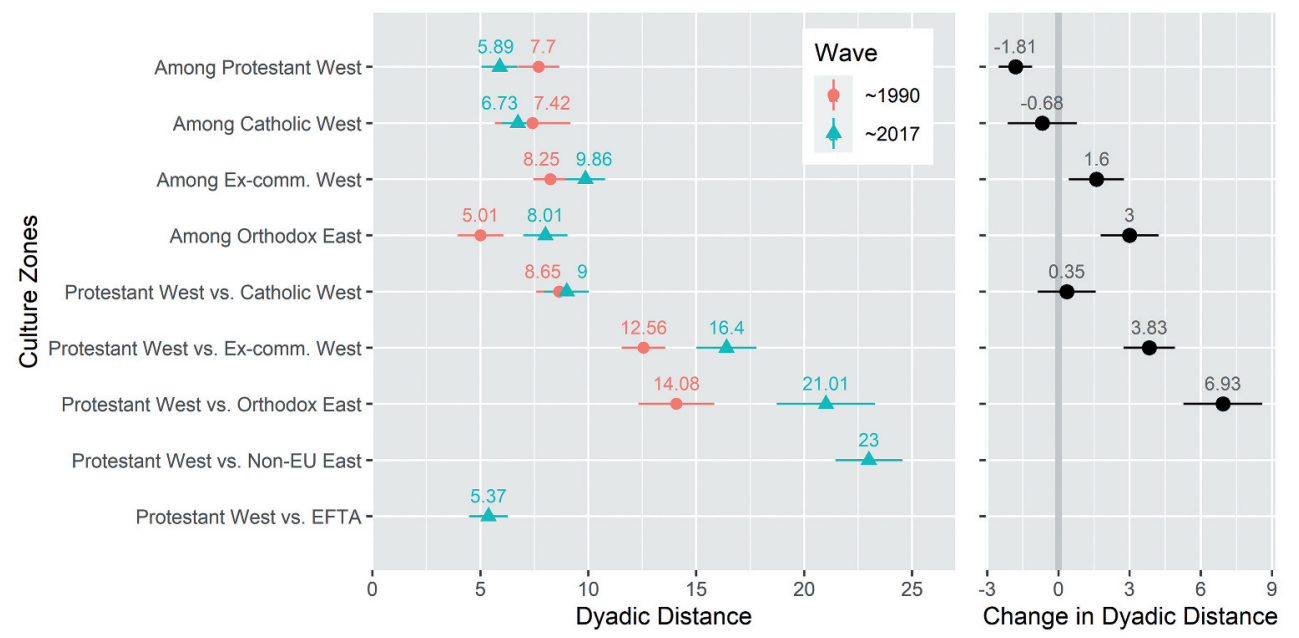

Figure 5. Dyadic distances and change in total distances in EU-values among and between groups of 19 EU, 7 Eastern European non-EU, and 3 EFTA non-EU-nations. Notes: Scores for non-EU East and EFTA countries were presented only for 2017 due to data limitations.

points). The average value distance between Protestant Western nations across the EU and EFTA is the smallest of all comparisons. This suggests that a shared cultural heritage and similar level of socio-economic development may bring similarity, regardless of the different level of involvement in the EU.

Figure 6 presents evidence that EU-publics are distinct from non-EU publics, albeit in opposite directions from Eastern and Western European non-members. The distance from Eastern European non-members is significant in four domains and is notably large in gender equality and personal freedom - 31 and 25.7 points, respectively. The three Western European nations outside the EU score higher on all seven EU-value domains than the EU average, although the difference is statistically significant only on individual autonomy. On EU-values as a whole, the statistically significant distance of 12.2 points from Eastern non-EU-nations and 10.8 from Western non-EU nations supports $\mathrm{H} 5$ stating that EU-nations are culturally distinct from non-EU-nations.

Using multidimensional scaling, Figures 7 and Figures 8 visualize Europe's cultural configuration in 1990 and 2017. National clusters are easily sorted out along the Protestant-vs-Catholic West distinction in Figure 1. The ex-communist countries, for their part, do not yet cluster as densely along the West-vs.-East distinction in 1990.

By 2017, the culture zones have become more compact and easily distinguishable. Especially, the Protestant and Catholic Western zones both appear homogeneous and closely located to each other on the map. The Ex-communist Western nations scatter over a larger area but also occupy a distinct cultural space. The two Orthodox EU-nations in our sample, Bulgaria and Romania, have drifted away (in relative terms) from the Excommunist West and now cluster with the Orthodox East outside the EU. Protestant nations outside the EU cluster well with the other nations of the Protestant West. These 

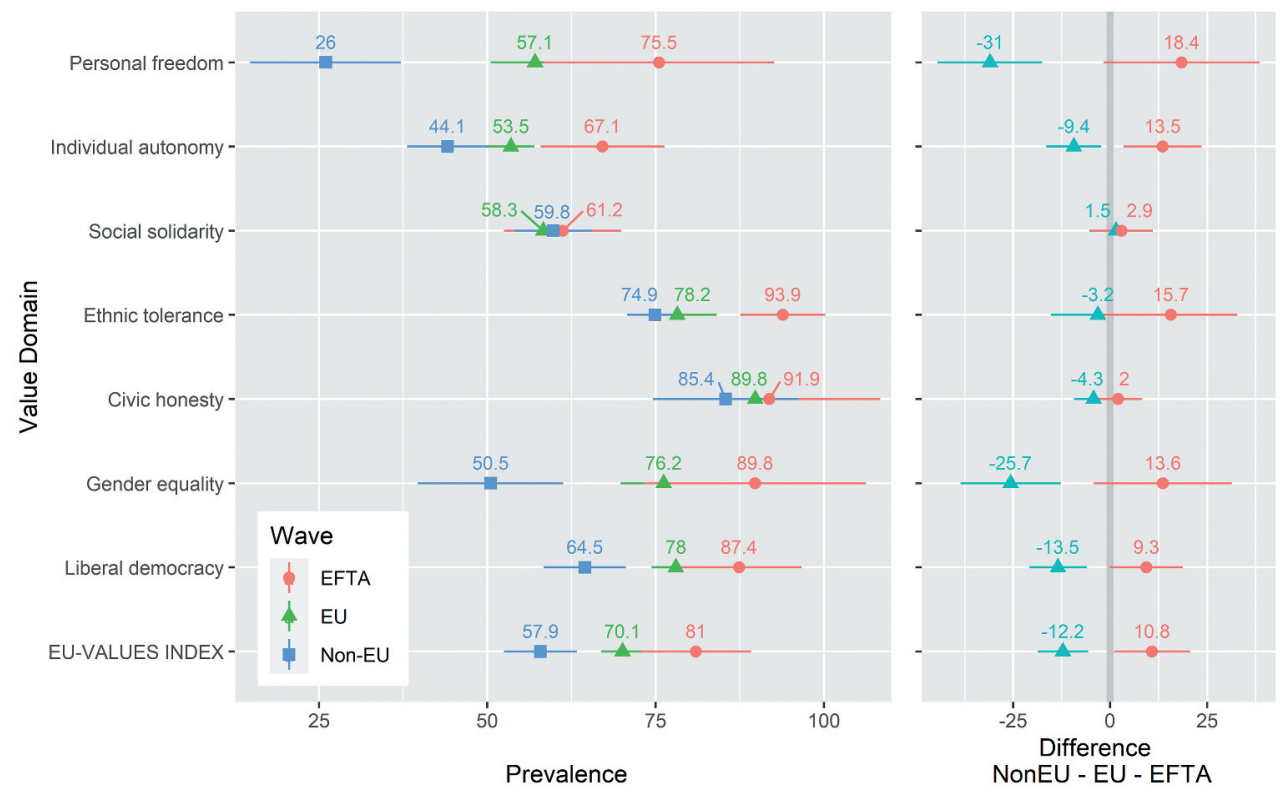

Figure 6. Prevalence of EU-values among 19 EU, 7 Eastern European non-EU, and 3 EFTA non-EUnations.

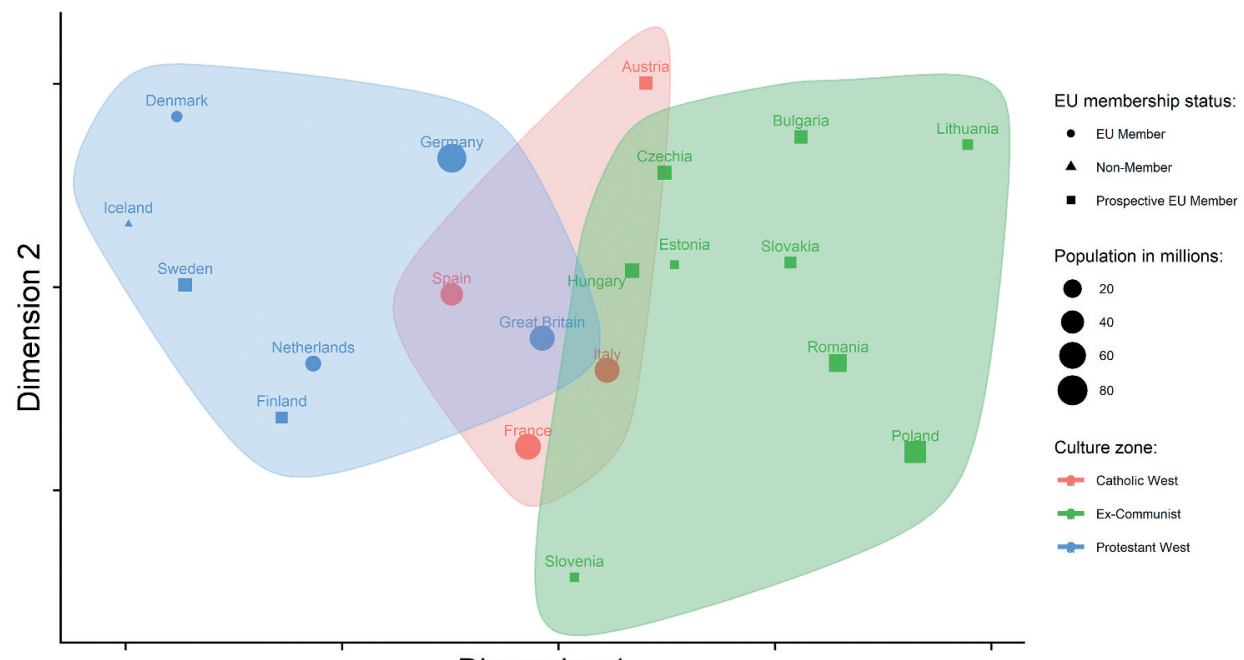

Dimension 1

Figure 7. Cultural map of Europe and grouping by culture zones in 1990. Notes: Loss criterion .13. Data: EVS, 1990-2017. Dimensions lack substantive meaning; for their correlations with EU-value domains, see Table 2.

cultural maps illustrate the continuing saliency of religious legacies beyond EU borders. Overall, the EU appears culturally distinct and this distinction is mostly due to the cultural position of the Protestant and Catholic nations. The European nations cluster within their respective culture zone, regardless if they belong to the EU or not. 


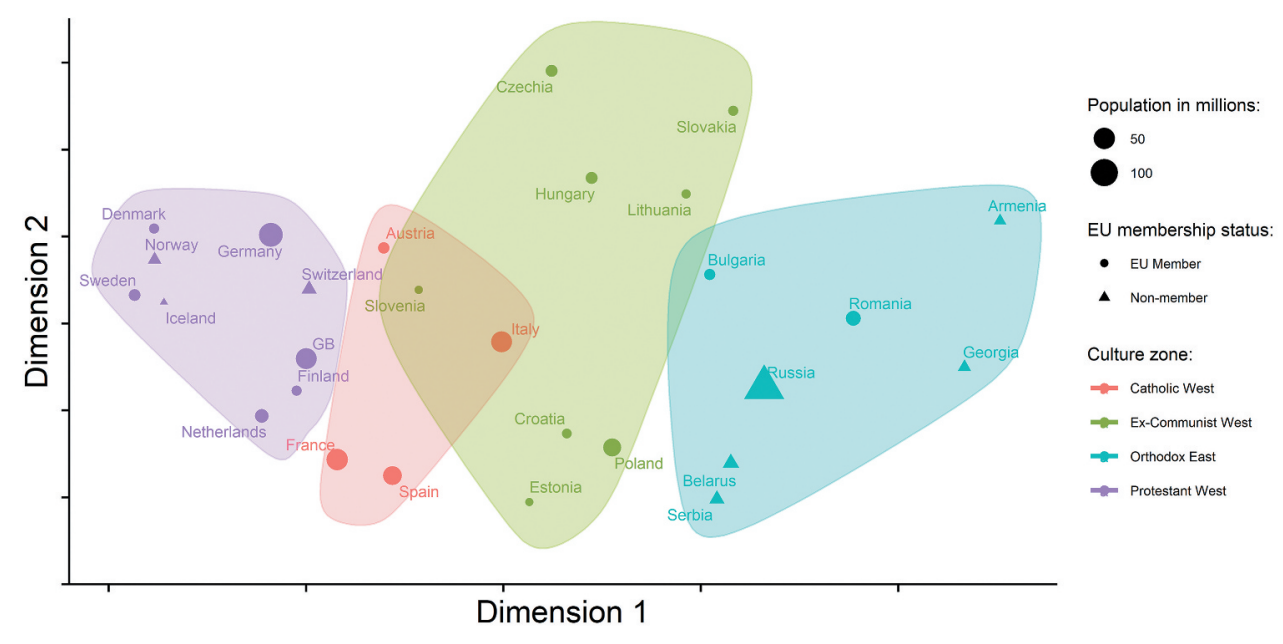

Figure 8. Cultural map of Europe and grouping by culture zones in 2017. Notes: Loss criterion 09 . Data: EVS, 1990-2017. Dimensions lack substantive meaning; for their correlations with EU-value domains, see Table 2 .

Table 2. Correlation matrix between the coordinates on the two-dimensional plot and EU-values and domains in 2017.

\begin{tabular}{lcc}
\hline & Dimension 1 & Dimension 2 \\
\hline Dimension 1 & 1 & \\
Dimension 2 & -0.07 & 1 \\
Personal freedom & -0.78 & -0.11 \\
Individual autonomy & -0.45 & -0.45 \\
Social solidarity & -0.02 & 0.23 \\
Ethnic tolerance & -0.71 & 0.48 \\
Civic honesty & -0.29 & 0.03 \\
Gender equality & -0.81 & 0.21 \\
Liberal democracy & -0.86 & -0.03 \\
EU-VALUES INDEX & -0.87 & 0.08 \\
\hline
\end{tabular}

Clearly, the four culture zones are more strongly distinguishable on Dimension 1: the closer clusters are to the left side of the dimension, the stronger they have internalized EU-values. We support this point by presenting a correlation matrix between the coordinates on the two-dimensional plot and the EU-values (Table 2). Dimension 1 indeed correlates with EU-values at $r=-.87$, and it correlates with almost all value domains more strongly than Dimension 2.

Table 3 summarizes the conclusions regarding all five hypotheses. The Support Hypothesis $(\mathrm{H} 1)$ is entirely confirmed in all tests. The Increase $(\mathrm{H} 2)$ and the Distinction Hypotheses ( $\mathrm{H} 5$ ) are confirmed overall but less conclusively because the answer depends on the value domain, while the Consensus $(\mathrm{H} 3)$ and the Convergence Hypotheses $(\mathrm{H} 4)$ are overall disconfirmed but not in all domains. 
Table 3. Summary of findings.

\begin{tabular}{|c|c|}
\hline Hypothesis & Finding \\
\hline $\begin{array}{l}\text { Support (H1): EU-member states support the EU- } \\
\text { values }\end{array}$ & Confirmed overall and on all 7 value domains \\
\hline $\begin{array}{l}\text { Increase }(\mathrm{H} 2) \text { : Support for EU-values has } \\
\text { increased among member states }\end{array}$ & Confirmed on average and on 4 out of 7 value domains \\
\hline $\begin{array}{l}\text { Consensus }(\mathrm{H} 3) \text { : Value distances between } \\
\text { member states are small }\end{array}$ & $\begin{array}{l}\text { Disconfirmed overall and especially on } 3 \text { out of } 7 \text { value domains } \\
\text { and between culture zones }\end{array}$ \\
\hline $\begin{array}{l}\text { Convergence }(\mathrm{H} 4) \text { : Value distances between } \\
\text { member states have decreased }\end{array}$ & $\begin{array}{l}\text { Disconfirmed overall: confirmed on } 1 \text { out of } 7 \text { value domains but } \\
\text { disconfirmed on } 4 \text { others and between culture zones }\end{array}$ \\
\hline $\begin{array}{l}\text { Distinction (H5): Support for EU-values separates } \\
\text { EU-member states from non-members }\end{array}$ & $\begin{array}{l}\text { Confirmed on average and on } 4 \text { value domains regarding Eastern } \\
\text { non-EU nations; EU is distinct also from Western non-EU nations } \\
\text { but in the opposite direction }\end{array}$ \\
\hline
\end{tabular}

\section{Discussion}

Overall, European publics largely endorse the values that the EU officially propagates in its treaties. EU-nations embrace these values significantly stronger than non-EU nations in Eastern Europe. Still, culture zone belongingness appears to be more important than institutional membership/non-membership in the EU to determine a public's stance to the values advocated by the EU. This is obvious from the EU-publics' divisions over these values across the Protestant-Catholic-Orthodox cleavage and, even more so, by the fact that non-EU publics belonging to the Protestant West (i.e. the EFTA-publics) endorse the EU-values just as strongly as the EU-nations that also belong to the Protestant West.

The EU's cultural distinction is particularly pronounced when it comes to values related to emancipation, especially personal freedom and gender equality. These are the value domains on which member nations show substantial growth in support over the last three decades. This finding confirms a previous study by Akaliyski and Welzel (2020) who argue that emancipative values have become the EU's trademark in the geopolitical competition with Russia and its new alliance. Publics may intuitively feel to be on moral high ground when having the pole position in the EU's emancipative values, which creates an ethically rewarding and psychologically satisficing 'normative leadership effect' that feeds its own acceleration. The high support for EU-values among Icelanders, Norwegians and Swiss suggests that value consensus may derive more from feelings of belongingness to the same 'family of nations' (i.e. mature Western democracies) in cultural terms than from mere membership in institutional terms, in addition to a high standard of living and access to education, which is conducive to emancipative values (Welzel 2013). It might, however, also be partly due to these nations being EFTA members and hence having adopted many of the regulations of the EU, although the latter proposition seems less plausible because it presumes that public opinion is shaped by law-making, all the while most people are not even aware of the laws governing them. In sum, claims from previous literature suggesting the impact of socioeconomic modernization (e.g. Welzel 2013), EU-membership (Akaliyski 2019) and Western cultural identity (Akaliyski and Welzel 2020) are all compatible with our findings.

Despite an overall rise in support of EU-values, EU-publics are nevertheless increasingly divided. Except ethnic tolerance where we find a noticeable decline among some member publics (especially in the Ex-communist West), the divergence 
is mostly the result of different speeds of value internalization among EU's distinct culture zones. Again, the growing divergence between culture zones is not because some nations have become less supportive of the EU-values (except for ethnic tolerance in some countries), but due to the different speeds of value change between them. In line with most previous studies, we confirm that Protestant nations are on the frontline of the cultural change, regardless if they are members of the EU or EFTA. The Protestant nations in the North are followed by the Catholic ones in the South and East at a slower speed. Nations in the Orthodox East, whether EUmembers or not, are completely off the cultural trajectory of the EU majority. Indeed, the Orthodox nations' cultural distance from the bulk of the EU has increased.

These findings align with previous claims about the continuous impact of cultural legacies on the development of modern societies (Inglehart and Baker 2000). Despite finding significant differences between religiously defined culture zones, we do not suggest a direct causal relationship between religion and values. Developmental and cultural differences in Europe existed centuries ago, even before the Reformation, and the split of Western Christianity into Roman Catholicism and Protestantism in the 16th century might be the result of these pre-existing cultural and economic differences. Similarly, some historians depict differences between Western, Central and Eastern Europe centuries before the onset of Communism (Szúcs 1983). However, even at present, religion and history are important sources of social identity that may continue to drive cultural change in Europe (Akaliyski and Welzel 2020).

Moreover, religion may reinforce previously existing cultural values through its prescriptions and practices that have become ingrained in culture even in societies where religion has lost its vitality due to secularization. Max Weber argued over a century ago that the different work ethics of the major branches of Christianity are all connected to different approaches to individualism and rationality that can be linked to different ascendance models (Weber 1988). While Protestantism is most in tune with rational modernity, Orthodox Christianity even today displays a 'sharp critique of individuality thought to be associated with Western developments' (Makrides 2012: 260). Catholicism falls in between the two extremes. This matches neatly with the cultural dynamics within the EU that we find. Recent work on the expansion of the EU and the underlying transnational-party networks that facilitated integration and their conflicts over the precise cultural ideology and image of Europe that should shape integration goes hand in hand with these findings (Hien and Wolkenstein 2021).

Various other indirect effects could contribute to explaining the difference in the prevalence and speed of change among cultural regions. First, the effect of EU-value promotion may be mediated by the degree to which countries identify with the EU (Zapryanova and Surzhko-Harned 2016). Publics that historically belong to Western Christianity, and especially those that did not experience communism, may identify more closely with Western cultural traditions and, therefore, be more susceptible to the EU's value promotion (Akaliyski and Welzel 2020). This may also be a result of the differential acceptance from within the Western community. According to Klingemann and Weldon (2013), the ex-communist countries that joined the EU in 2004 were less trusted by the founding members but substantially more so than the two Orthodox countries that joined in 2007 (Bulgaria and Romania). Those two countries, in turn, 
received a great amount more trust than Turkey. This gradation in trust could explain the decreasing acceptance of EU-values as one goes further away from what seems to be the EU's cultural pacemaker: the Protestant West.

Another potential explanation is the idea of a cultural backlash. Fast cultural and institutional change may trigger a response from parts of the population feeling 'left behind' or like 'strangers in their own land,' known as the 'authoritarian reflex.' This response may drift them into the opposite direction to that of the majority's emancipatory dynamic (Inglehart 2018; Norris and Inglehart 2019). This cultural sorting-out process might also operate among entire nations within the EU. Since the collapse of communism was the beginning of radical societal transformations in the EU's Eastern member states, the speed and intensity of change may have caused a distress among large shares of their populations. The reaction may be to distance themselves from the pace-making Protestant countries, which keep pushing for a firmer commitment to EUvalues. Consequently, it is plausible that such cultural backlash among segments of the newer member states, especially older generations, has slowed down their value change on the average compared to Western European member states. However, despite popular concerns, especially regarding Hungary and Poland, we find no evidence that the populations of the new member states have turned their back to EU-values on average (with the exception of ethnic tolerance). In other words, different speeds on a common ascending trajectory of cultural change result in value divergence among member states.

Regardless of the reasons, our findings suggest that both the growing geopolitical tension between the EU and its Eastern neighbours and the growing tensions within the EU are not just the result of conflicting economic interests. Instead, the apparent disagreements may unfold on the basis of deeper-layered and evidently growing divides over values. These value differences become especially salient during crises - such as the financial crisis that divided Northern and Southern European countries, the refugee crisis that divided Western and Eastern European member states and the rule of law crisis that placed the spotlight on some newly accessed Eastern European members. On the other hand, crises always embody the opportunity for change to the better. By becoming fully aware of its built-in value architecture and the deep historical roots underlying it, the EU community may find a way either to adjust decision-making to reflect the fundamental cultural differences between EU societies or to successfully diminish them over the course of continuous integration.

\section{Disclosure statement}

No potential conflict of interest was reported by the author(s).

\section{Funding}

The work of the second author was supported by the HSE University Basic Research Program. 


\section{ORCID}

Plamen Akaliyski (iD) http://orcid.org/0000-0002-0157-0246

\section{References}

Akaliyski, P. 2017. "Sources of Societal Value Similarities across Europe: Evidence from Dyadic Models." Comparative Sociology 16 (4): 447-470. doi:10.1163/15691330-12341432.

Akaliyski, P. 2019. "United in Diversity? the Convergence of Cultural Values among EU Member States and Candidates." European Journal of Political Research 58 (2): 388-411. doi:10.1111/14756765.12285.

Akaliyski, P., and C. Welzel. 2020. "Clashing Values: Supranational Identities, Geopolitical Rivalry and Europe's Growing Cultural Divide." Journal of Cross-Cultural Psychology 51 (9): 740-762. doi:10.1177/0022022120956716.

Akaliyski, P., M. H. Bond, and C. Welzel. 2021. “Nations as Gravitational Fields of Culture: In Defence of "Nationology"." SocArXiv. doi:10.31235/osf.io/94msk.

Aronow, P. M., C. Samii, and V. A. Assenova. 2015. "Cluster-Robust Variance Estimation for Dyadic Data." Political Analysis 23 (4): 564-577. doi:10.1093/pan/mpv018.

Bonikowski, B. 2010. "Cross-national Interaction and Cultural Similarity: A Relational Analysis." International Journal of Comparative Sociology 51 (5): 315-348. doi:10.1177/ 0020715210376854.

Borg, I., P. J. F. Groenen, and P. Mair. 2013. Applied Multidimensional Scaling. Heidelberg: Springer.

Cameron, A. C., J. B. Gelbach, and D. L. Miller. 2011. "Robust Inference With Multiway Clustering." Journal of Business and Economic Statistics 29 (2): 238-249. http://www.jstor.org/stable/25800796. doi:10.1198/jbes.2010.07136.

Fischer, R. and Schwartz S. 2011. "Whence Differences in Value Priorities?: Individual, Cultural, or Artifactual Sources." Journal of Cross-Cultural Psychology 42 (7): 1127-1144. 10.1177/ 0022022110381429

Fuchs, D., and H. D. Klingemann. 2002. "Eastward Enlargement of the European Union and the Identity of Europe." West European Politics 25 (2): 19-+. doi:10.1080/713869598.

Gerhards, J. 2007. Cultural Overstretch? Differences between Old and New Member States of the EU and Turkey. London: Routledge.

Gerhards, J, M S Schafer, and S Kampfer. 2009. "Gender Equality in the European Union: The EU Script and Its Support by European Citizens." Sociology-the Journal of the British Sociological Association 43 (3): 515-534. doi:10.1177/0038038509103206

Gerhards, J. 2010. "Non-Discrimination towards Homosexuality: The European Union's Policy and Citizens' Attitudes towards Homosexuality in 27 European Countries." International Sociology 25 (1): 5-28. doi:10.1177/0268580909346704.

Gerhards, J., and M. Hoelscher. 2003. "Cultural Differences between Present and Future Member Countries of the European Union - the Example of Family and Gender Concepts." Zeitschrift Fur Soziologie 32 (3): 206-225. doi:10.1515/zfsoz-2003-0302.

Guiso, L., H. Herrera, and M. Morelli. 2016. "Cultural Differences and Institutional Integration." Journal of International Economics 99: S97-S113. doi:10.1016/j.jinteco.2015.11.005.

Habermas, J. 2012. The Crisis of the European Union: A Response. Princeton, NJ: Polity Press.

Hellquist, E. 2019. "Ostracism and the EU's Contradictory Approach to Sanctions at Home and Abroad." Contemporary Politics 25 (4): 393-418. doi:10.1080/13569775.2018.1553083.

Hellquist, E., and S. Palestini. 2020. "Regional Sanctions and the Struggle for Democracy: Introduction to the Special Issue." International Political Science Review. doi:10.1177/ 0192512120968109.

Hien, J. 2019. "The Religious Foundations of the European Crisis." Journal of Common Market Studies 57 (2): 185-204. doi:10.1111/jcms.12635.

Hien, J., and F. Wolkenstein. 2021. "Where Does Europe End? Christian Democracy and the Expansion of Europe." JCMS: Journal of Common Market Studies. doi:10.1111/jcms.13206. 
Inglehart, R. 1997. Modernization and Postmodernization: Cultural Economic and Political Change in 43 Societies. Princeton, NJ: Princeton University Press.

Inglehart, R., and C. Welzel. 2005. Modernization, Cultural Change, and Democracy: The Human Development Sequence. Cambridge, UK: Cambridge University Press.

Inglehart, R., and W. E. Baker. 2000. "Modernization, Cultural Change, and the Persistence of Traditional Values." American Sociological Review 65 (1): 19-51. doi:10.2307/2657288.

Inglehart, R. F. 2018. Cultural Evolution: People's Motivations Are Changing, and Reshaping the World. Cambridge, UK: Cambridge University Press.

Kelemen, R. D. 2020. "The European Union's Authoritarian Equilibrium." Journal of European Public Policy 27 (3): 481-499. doi:10.1080/13501763.2020.1712455.

Kirsch, H., and C. Welzel. 2019. "Democracy Misunderstood: Authoritarian Notions of Democracy around the Globe." Social Forces 98 (1): 59-92. doi:10.1093/sf/soy114.

Klingemann, H. D., and S. Weldon. 2013. "A Crisis of Integration? the Development of Transnational Dyadic Trust in the European Union, 1954-2004." European Journal of Political Research 52 (4): 457-482. doi:10.1111/1475-6765.12005.

Kochenov, D. 2017. "The Acquis and Its Principles: The Enforcement of the 'Law' versus the Enforcement of 'Values' in the European Union." In The Enforcement of EU Law and Values, edited by A. Jakab and D. Kochenov, 9-27, Oxford University Press, Oxford, UK.

Lahdesmaki, T. 2016. "Politics of Tangibility, Intangibility, and Place in the Making of a European Cultural Heritage in EU Heritage Policy." International Journal of Heritage Studies 22 (10): 766-780. doi:10.1080/13527258.2016.1212386.

Makrides, V. (2012) "Orthodox Christianity, Modernity and Postmodernity: Overview, Analysis and Assessment', Religion'. State and Society 40 (3-4): 248-285.

Manners, I. 2002. "Normative Power Europe: A Contradiction in Terms?." Journal of Common Market Studies 40 (2): 235-258. doi:10.1111/1468-5965.00353.

Minkov, M., and G. Hofstede. 2012. "Is National Culture a Meaningful Concept? Cultural Values Delineate Homogeneous National Clusters of In-Country Regions." Cross-Cultural Research 46 (2): 133-159. doi:10.1177/1069397111427262.

Minkov, M., and G. Hofstede. 2014a. “Clustering of 316 European Regions on Measures of Values: Do Europe's Countries Have National Cultures?." Cross-Cultural Research 48 (2): 144-176. doi:10.1177/ 1069397113510866.

Minkov, M., and G. Hofstede. 2014b. "Nations versus Religions: Which Has a Stronger Effect on Societal Values?." Management International Review 54 (6): 801-824. doi:10.1007/s11575-0140205-8.

Norris, P. and Inglehart, R. 2019. Cultural Backlash Trump, Brexit, and the Rise of Authoritarian Populism. Cambridge, UK: Cambridge University Press.

Oshri, O., T. Sheafer, and S. R. Shenhav. 2016. "A Community of Values: Democratic Identity Formation in the European Union." European Union Politics 17 (1): 114-137. doi:10.1177/ 1465116515608957.

Schwartz, S, and A Bardi. 1997. "Influences of Adaptation to Communist Rule on Value Priorities in Eastern Europe." Political Psychology 18 (2): 385-410. doi:10.1111/0162-895x.00062

Schwartz, S. H. 2006. "A Theory of Cultural Value Orientations: Explication and Applications." Comparative Sociology 5 (2-3): 137-182. doi:10.1163/156913306778667357.

Schwartz, S. H. 2014. "Rethinking the Concept and Measurement of Societal Culture in Light of Empirical Findings." Journal of Cross-Cultural Psychology 45 (1): 5-13. doi:10.1177/ 0022022113490830.

Sen, A. 1999. Development as Freedom. A Knopf. New York.

Spieker, L. D. 2019. "Breathing Life into the Union's Common Values: On the Judicial Application of Article 2 TEU in the EU Value Crisis." German Law Journal 20 (8): 1182-1213. doi:10.1017/ glj.2019.84. Cambridge University Press.

Szűcs, J. 1983. "The Three Historical Regions of Europe: An Outline." Acta Historica Academiae Scientiarum 29 (2/4): 131-184. http://search.ebscohost.com/login.aspx?direct=true\&db= hia\&AN=46195648\&amp\%5Cnlang=fr\&site=ehost-live . 
Toggenburg, G. N., and J. Grimheden. 2016. "Upholding Shared Values in the EU: What Role for the EU Agency for Fundamental Rights?." Journal of Common Market Studies 54 (5): 1093-1104. doi:10.1111/jcms.12404.

van Houwelingen, P., J. ledema, and P. Dekker. 2019. “Convergence on Political Values? A Multi-level Analysis of Developments in 15 EU Countries 2002-2016." Journal of European Integration 41 (5): 587-604. doi:10.1080/07036337.2018.1537270.

van Houwelingen, P., P. Akaliyski, P. Dekker, and J. ledema. 2021. “Convergence or Divergence? A Multilevel Analysis of Political Values in 18 EU Countries 1990-2017." Comparative European Politics. doi:10.1057/s41295-021-00241-w.

Welzel, C. 2013. Freedom Rising: Human Empowerment and the Quest for Emancipation. Cambridge: Cambridge University Press.

Welzel, C., L. Brunkert, S. Kruse, and R. F. Inglehart. 2021. "Non-invariance? an Overstated Problem with Misconceived Causes." Sociological Methods \& Research 50. doi:10.1177/0049124121995521.

Wolkenstein, F. 2021. "European Political Parties' Complicity in Democratic Backsliding." Global Constitutionalism 1-28. doi:10.1017/S2045381720000386.

Zapryanova, Galina M, and Surzhko-Harned, L. 2016. "The Effect of Supranational Identity on Cultural Values in Europe."European Political Science Review 8 (4). Cambridge, UK: Cambridge University Press: 547-566. doi:10.1017/S1755773915000193 